Руселина Ницолова

Софийский университет „Св. Климент Охридский“ nitsolova@abv.bg
УДК 811.163.2'36

https://doi.org/10.18485/slavistika.2018.22.1.6

оригинални научни рад примљено 28.02.2018.

прихваћено за штампу 19.05.2018

\title{
О ФАКТОРАХ, ПРЕПЯТСТВУЮЩИХ ГРАММАТИКАЛИЗАЦИИ
}

Грамматикализация - это градуальный внутриязыковой процесс изменений, который может продолжаться в течение длительного исторического периода и вести к появлению новой граммемы. Исходным элементом при грамматикализации может быть лексема или сочетание лексем, а также другая граммема. В статье рассматриваются случаи неуспешных грамматикализаций в болгарском языке и некоторые факторы, которые препятствуют грамматикализации: лексическое значение исходного элемента и связанные с ним конвенциональные импликации, семантическая и грамматическая комбинаторика в конструкции, разные отношения грамматикализирующегося элемента с грамматической системой и языковой системой в целом, социолингвистические факторы и др.

Ключевые слова: грамматикализация, препятствующие ей факторы, болгарский язык.

Grammaticalization is a gradual internal linguistic process of change that can take a long time and results in the appearance of a new grammeme. The starting point is a lexeme or a combination of lexemes, or another grammeme. The article discusses cases of failed grammaticalizations in Bulgarian and some of the factors preventing the process: the lexical meaning of the initial elements and the conventional implicatures connected with it, collocation and colligation restrictions, various types of relations of the element undergoing grammaticalization and the particular grammatical system or the language system in general, sociolinguistic factors, etc.

Key words: grammaticalization and factors preventing it, Bulgarian.

0.1. Грамматикализация является уже столетным термином в лингвистике, начало которого связывается с известной работой А. Мейе L'évolution des formes grammaticales (Meillet 1912), но особенно интенсивно он начинает употребляться во второй половине прошлого века. В настоящее время литература о граматикализации в самых различных языках необозрима, существует отдельный словарь (Heine, Kuteva 2002), насчитывающий около 400 грамматикализаций в языках мира. Несмотря на это, в теории грамматикализации все еще существует много нерешенных проблем, которые подробно обсуждаются в работах современных исследователей (Wiemer, Wälchli 2011; Wiemer 2014). Возникает вопрос о том, что большинством ученых, исследующих грамматикализацию, к настоящему времени признается бесспорным? Грамматикализация - это градуальный внутриязыковой процесс изменений, который может продолжаться в течение долгого исторического периода и вести к появлению новой граммемы. Эта граммема развивается либо из лексемы или сочетания лексем, либо из другой граммемы. Вишер говорит в своей дефиниции грамматикализации и о фонетических элементах, которые превращаются в грамматические (Wischer 2006: 129). Разницу между начальной и конечной граммемами ищут в степени грамматичности, определяя ее разным способом (см. Kuryłowicz 1965: 55-71; Brinton, Traugot 2005: 99; Wischer 2006: 129 и др.). Степень грамматичности - понятие, которое очень проблематично, и в последнее время его начинают избегать, говоря лишь о новом грамматическом значении, что является более точным в данном случае. 
Кутева и Хайне в своей известной работе конкретизируют результаты грамматикализации следующим образом: (i) создается новая категория; (ii) замещаются старые средства выражения грамматического значения новыми средствами (Kuteva, Heine 2012: 161). К этому можно добавить и исчезновение определенной категории, напр. исчезновение грамматического рода в тамианском диалекте латышского (индоевропейского) языка под влиянием ливонского (угро-финского) субстрата или адстрата, в котором нет грамматического рода (Wiemer, Wälchli 2012: 31, а также цит. в этой работе литература). Авторы считают исчезновение определенной грамматической категории не грамматикализацией, а реструктурированием, но подчеркивают и то, что случаи реструктурирования можно считать и случаями грамматикализации, так что не совсем ясно различие между этими двумя понятиями (Heine, Kuteva 2006: 67-68).

Одна из новых дефиниций грамматикализации, предложенная Бойе и Хардером (Boye, Harder 2012), стремится разграничить грамматические от лексических явлений: грамматические явления обычно вспомагательны и дискурсивно вторичны, а лексические существенны и дискурсивно первичны. Ср. „Грамматикализация - диахроническое изменение, дающее начало языковым выражениям, которые обычно вспомагательны и, в качестве таковых, дискурсивно вторичны (Boye, Harder 2012: 21, цит. по Wiemer 2014). Это определение, как и множество других, не разграничивает грамматикализацию от других языковых изменений, таких как аналогия, метафора, метонимия, реструктурирование и др., репертуар которых пока даже не уточнен.

Если речь идет о протекании процесса грамматикализации, важно отметить, что существует относительная самостоятельность ее развития с формальной (фонетической и морфологической ) и семантической и функциональной точек зрения. Кроме того, надо подчеркнуть, что индивидуальные изменения при грамматикализации проявляются на фоне исторического развития фонетической и грамматической системы языка, так что, как правило, в одной и той же конструкции эти два вида изменений совмещаются. При этом очень часто изменяется не только исходный элемент, но и вся конструкция, в которой он находится. Хороший пример вышеизложенного представляет очень длительное формальное развитие футурных форм современного болгарского и других южнославянских языков из древнеболгарских инфинитивных конструкций с глаголами hotěti и iměti, напр. болг. ще пея 'буду петь' и няма да пея 'не буду петь', серб. певаћу, ја ћу певати, ја нећу певати, хорв. рјеvаt с́и (см. подр. Мирчев 1976: 224; ГСЕ 1991; Ницолова 2012, 2014).

Развитие процесса грамматикализации очень сложно, так как в нем имеет место множество самых различных процессов, связанных с особенностями языков разной грамматической структуры. Кутева и Хайне (Kuteva, Heine 2012: 162) определяют основные параметры грамматикализации следующим образом:

a) экстензия (или контекстная генерализация): употребление в новых контекстах ведет к новым значениям;

б) десемантизация (или semantic bleaching - семантическое обесцвечивание), т.е. изменение лексического содержания; 
в) декатегоризация, т.е. исчезновение морфо-синтаксических особенностей, характерных для лексических или других менее грамматикализированных форм;

г) эрозия (или „фонетическая редукция“), т.е. потеря фонетической субстанции

В некоторых случаях при грамматикализации наблюдается и формальная декомпозиция, и реанализ, напр. грамматикализация сочетания имени существительного с указательным местоимением, которое превратилось в сочетание имени с определенным артиклем в болгарском языке, ср. древнеболг. сочетание рабъ тъ 'этот раб' и современную болгарскую определенную форму роба [ро́бъ] без -т, в которой морфемная граница перемещена и показателем детерминации фактически является старое окончание имен. пад. $о$-основ мужского рода, а не исчезнувшее в этой форме указательное местоимение. Окончание -ъ во всех других случаях исчезло по фонетическим причинам (действовал закон о выпадении слабых еров), но в этом случае из-за своей позиции ерь уже не был слабым и сохранился, принимая новое значение детерминатора после распада болгарской падежной системы.

Специальное внимание нужно уделить вопросу интеграции новой граммемы в языковую систему, с одной стороны, и, с другой стороны, в узус, т.е. конкуренции с синонимическими средствами, употреблению в разных стилях и регистрах и т.д. Речь идет о процессе, который может продолжаться на протяжении веков. На современном этапе развития болгарского литературного языка можно наблюдать как постепенно в разных синтаксических позициях устанавливается оппозиция между неопределенным артиклем един и нулевым артиклем и, с другой стороны, между един и определенным артиклем в сочетании с существительными с разным лексическим значением при обозначении разных видов детерминации, напр. при генерической детерминации эти оппозиции все еще не совсем установились (см. подр. Ницолова 2017: 131-172).

Не всегда, однако, грамматикализация достигает своих целей. В истории языков были попытки грамматикализации определенных конструкций, но они оказались не совсем удачными. При этом, исходя из развития не только болгарского языка, можем обособить три возможных случая:

1) попытки грамматикализации определенных конструкций очень быстро прекращаются из-за конкуренции с грамматикализацией других более успешных конструкций, напр. попытка обозначить будущие действия при помощи сочетания инфинитива с глаголами, обозначающими начало действия načęnti, vâčęnti в древнеболг. языке;

2) процесс грамматикализации начинается, существует кратковременно и прекращается, так как не могут развиться все ее параметры (другой набор параметров указан, например, в работе Lehmann 2002: 110), такая грамматикализация оставляет лишь изредка отдельные следы, зачастую идиоматического характера, напр. так называемый презумптив и синтетическое условное наклонение в болгарском языке;

3) грамматикализации не могут достичь полного развития, но все-таки продолжают существовать, иногда лишь в стилистически или прагматически ограниченной сфере употребления, напр. посессивный перфект и экзистенциальный 
пассив в болгарском языке - посессивный перфект встречается в административно-деловом стиле и в публицистических сообщениях административно-делового характера, в письменной и, реже, устной речи (подобное употребление посессивного перфекта встречается и в македонском, сербском, украинском языках, см. Номати 2012, 2015 и др.; Поповић 2014; Митковска, Бужаровска 2008).

Экзистенциальный пассив также используется преимущественно в публицистическом и административном стилях, но он свободно употребляется, хотя и реже, в разговорной речи и художественных произведениях. Надо, однако, разграничивать такие случаи от случаев грамматикализации, которая представляет сложный градуальный процесс с относительно самостоятельным развитием в формальном и семантическом отношениях и на данный момент еще не достигла своей конечной степени развития и полноты в качественном и количественном отношениях.

Факторы, препятствующие грамматикализации в языках, очень разнородны и часто проявляются в самых различных сочетаниях. Здесь рассмотрим несколько таких факторов на материале грамматикализации как лексических, так и грамматических элементов из истории болгарского языка.

1. Начнем со случая, когда препятствующим фактором является лексическое значение исходного элемента и связанные с ним возможные конвенциональные импликации. Речь идет о попытках выражения будущего времени конструкциями с инфинитивом и глаголами начинательного значения načęnti, vâčenti в древнеболг. языке, которые были вытеснены конкурентными конструкциями с глаголами hotěti и iměti с модальным значением. Успех грамматикализации зависит не только от лексического значения начального элемента, но и от связанных с ним конвенциональных импликатур, которые могут привести именно к новому, грамматическому значению. Типичный пример конвенциональной импликатуры - это импликатура глагола $x$ отеть в разных языках типа -'X хочет сделать A', что имплицирует, что существует большая вероятность, что в будущем X сделает А. Значения хотеть и иметь связывались с импликацией, что, если одно действие желанно или необходимо, очень вероятно, что последует его совершение в будущем. Подобные грамматикализации существуют и в ряде европейских языков (Bybee et al.1994: 256-266, Wiemer, Hansen 2011: 109-110). В отличие от этих конструкций, конструкции с načęnti, vâčęnti в древнеболгарском языке продолжали сохранять начинательное значение первого глагола, редко связывались с импликацией о футурности действия и не могли превратиться в маркер будущего времени.

Если исходная конструкция при грамматикализации более сложна, существуют разные препятствующие факторы, связанные с семантической и грамматической сочетаемостью ее элементов. Очень хороший пример этого представляет в болгарском языке грамматикализация посессивного перфекта, который является одной из особенностей Standard Average European languages (Haspelmath 2001: 1495), напр. Имам написан текст по въпроса 'У меня написан текст по этому вопросу'. Болгарский посессивный перфект уже долгое время остается в начальной степени развития, близкой до идиоматики (о четырех степенях развития посессивного перфекта см. Heine, Kuteva 2006: 144-145), и вероятно не будет дальше развиваться, в отличие от подобного яв- 
ления в других языках. В данном случае речь идет о трехчленной конструкции с двумя предикатами - главный предикат глагол имам 'иметь' с посессивным значением, второстепенный предикат, выраженный страдательным причастием прош. вр., использован как определение к имени или именной группе. В этой трехчленной конструкции наблюдаются два вида семантических ограничений:

а) ограничения в сочетаемости глагола имам 'иметь' (у него сохранено посессивное значение) с его субъектом, которые связаны с тем, что семантика конструкции, как и семантика предложения и контекста и знания о мире, порождают импликацию того, что глагольный субъект является не только посессором, но и агенсом причастного глагола, напр.: Имам един завъриен проект 'У меня есть один завершенный проект’ (если слушатель знает, что говорящий, например, архитектор, он будет считать с большей вероятностью, что говорящий является и автором проекта), в отличие от: Имам предписани няколко лекарства 'Мне прописаны несколько лекарств', где субъект является бенефициентом, но не агенсом, так что в этом случае нет посессивного перфекта;

б) ограничения в сочетаемости глагола имам с его объектом обладания, который одновременно является и объектом действия страдательного причастия - налицо сильная идиосинкретичность, ср. Тази опера я имам записана 'У меня есть запись этой оперы (букв. записана эта опера)' и *Тази опера я имам слушана 'Я слушал эту оперу' (см. подр. Ницолова 2014);

в) кроме ограничений, связанных с семантической комбинаторикой элементов данной грамматикализации, существуют и грамматические ограничения: глагол страдательного причастия обязательно только транзитивен, страдательное причастие обязательно употребляется только с нулевым артиклем, несмотря на детерминацию его определяемого, которая может быть разного рода, страдательное причастие согласовывается в роде и числе со своим определяемым; существуют ограничения при употреблении некоторых темпоральных форм индикатива и других эвиденциалов глагола имам.

2. Очень сложной и не всегда успешной может оказаться грамматикализация, когда ее исходным элементом является грамматическая морфема или грамматическая форма. Первым нашим примером неуспешной грамматикализации является т. наз. синтетическое условное наклонение в болгарском языке. Оно образуется добавлением к основам наст. вр. или имперфекта индикатива морфем -вa-, $-a в a-,-a-$, т.е. это грамматические морфемы, которые являются прежде всего маркером несовершенного вида (см. Чакърова 1995), напр. пия-пийвам, пийвах; ям-ядвам, ядвах.

Напр. ... ако ни хванат тез чамурлийци, съдират ни от бой (Й. Йовков) - ' ... если бы нас поймали чамурляне, разорвали бы нас в клочья'; ...ако ви трябва, аз ви слушвам, и както искате, никога не блажвам...(П. Р. Славейков) - '...если бы вам было нужно, я бы вас слушал, и если бы вы захотели, то никогда бы не ел скоромного...'; Да беше друга, изпъжндах я (Й. Йовков) 'Если бы она была другой, я бы ее выгнал'.

Морфотактика болгарских глаголов, как и их лексическое значение, разрешает добавление указанных морфем лишь в некоторых случаях, преимущественно к основным глаголам и редко к основам некоторых других глаголов. 
Наблюдается и омонимия с формами вторичного несов. вида, вне контекста обычно форма с указанными суффиксами воспринимается как форма несов. вида в индикативе. С формальной точки зрения налицо существенные ограничения, а на семантическом морфемном уровне получается морфемная полисемия, которую грамматические системы стремятся устранять. На уровне морфологической семантики разграничение между синтетическим и аналитическим условным наклонением (с бux) не особенно отчетливо проявляется - первое называют условным наклонением готовности, а второе - условным наклонением возможности, но об этом можно дискутировать. Все эти факторы привели к тому, что синтетическое условное наклонение, которое, хотя и очень слабо продуктивно, но все-таки иногда встречалось в разговорной речи и в языке некоторых писателей XIX в. и первых десятилетий XX в., в настоящее время уже не употребляется, за исключением двух идиоматизированных форм ядвам и пийвам.

Второй пример - т.наз. презумптив, который в болгарском языке, как и в других языках, возник на основе двух времен индикатива: будущего и будущего предварительного, которые, соответствующе, обозначают предположение о настоящем и будущем действии. Из-за связанного с грамматикализацией реанализа их составную часть ще (да) начали воспринимать как маркер предположительности и стали также добавлять к формам других времен: наст. вр., перфекта, аориста, имперфекта, плюсквамперфекта. Из этой парадигмы презумптива, которая подана в работе Герджикова (1984: 121-153), в настоящее время в электронных ресурсах исключительно редко встречаются только формы наст. вр. и перфекта - это преимущественно формы съм 'быть' наст. вр., только один раз засвидетельствована форма имперфекта. Напр. Кой е Василчо? Не ще да e тоя възстар човек, когото виждаше сега (Й. Йовков) 'Кто такой Василчо? Наверно, это не тот пожилой человек, которого он сейчас видит'.

Фактором, препятствующим установлению презумптива, является глагольная система болгарского языка, структура которой семантически и формально исключительно сложна, так что одно новое наклонение еще больше увеличило бы ее сложность. Более сильным препятствующим фактором, однако, является структура болгарского языка в целом. Влияние системы языка при грамматикализации огромно. Болгарская глагольная система не приняла еще одну новую модальную парадигму, значение которой точно и даже более градуированно передается сочетанием времен индикатива с множеством модальных наречий, таких как вероятно 'вероятно, возможно', може би 'может быть', сигурно 'наверняка, наверное', едва ли 'едва ли, навряд ли' и др., или сочетанием основного глагола с модальными глаголами може 'может быть', трябва 'наверно', которые с разной степенью вероятности обозначают возможную истинность предположения. Наличие таких сильных синонимических конкурентов оказалось важным препятствующим фактором для грамматикализации презумптива, который был бы избыточным элементом в системе.

3. Важно подчеркнуть, что фактором, препятствующим полному развитию грамматикализации, может являться и дефективная информационная структура итоговой конструкции. Имеется ввиду так наз. экзистенциальный пассив, напр.: „По въпроса има написана статия" “По этому вопросу существует на- 
писанная статья'. Экзистенциальный предикат има обуславливает информационную структуру предложения, в которой нет дихотомии топик и фокус, т.е. предложение тетическое. Именная группа - прямое дополнение по этой причине не может быть топиком. На нее накладываются ограничения в сочетании с детерминаторами, и она не может быть вторично обозначена личным клитическим местоимением (репризой), см. подр. Ницолова (2016). Таким образом, у предложений с экзистенциальном пассивом с habere дефективна информационная парадигма, противопоставляющая их предложениям с пассивом с esse, у которых полная парадигма информационных структур.

4. Наконец, надо упомянуть и социолингвистические факторы, препятствующие развитию и особенно расширению грамматикализации определенного языкового явления. Речь идет о двух группах факторов:

a) положительная или отрицательная оценка данной грамматикализации разными слоями общества, различающимися, например, своим образованием, культурой, местожительством, профессией, возрастом, отношением к контактному иностранному языку или языкам, если существуют такие контакты и грамматикализация контактно индуцирована, и др.;

б) официальная языковая политика, выражаемая предписаниями языковой культуры лингвистами, обучением в школе, нормативностью в СМИ и письменной продукции и др.

Здесь рассмотрим два случая в истории болгарского литературного языка, когда лингвисты были против грамматикализаций, которые, несомненно или вероятно, контактно индуцированы иностранными языками: замещение вокативной формы личных имен общей формой и установление грамматикализованного един в качестве неопределенного артикля.

Начнем с замещения вокативной формы личных имен общей формой. В болгарском языке, как известно, существует аналитизм в области имен, т.е. нет падежной системы. Однако в нем все еще сохранились формы вокатива, которые выполняют прагматическую функцию, а не выражают синтаксические и семантические отношения, как остальные падежные формы. В первые десятилетия XX в. началось замещение вокативных форм личных женских имен общими формами, которые являются бывшими формами именительного падежа. Это замещение проявлялось лишь в разговорной речи образованных женщин, а позже и мужчин, которые получили свое образование вне Болгарии - в Германии, Франции, Англии или России. Несомненно речь идет о контактно- индуцированной грамматикализации, так как ни в немецком, ни во французском, ни в английском или русском языках не существует вокатив. Этот процесс очень хорошо описан и критически прокомментирован известным болгарским ученым акад. Младеновым (Младенов 1927-1928: 215-216). Так как в упомянутых выше языках нет вокатива, болгарки, получившие свое образование в соответствующих странах, начали считать, что вокатив - это просторечная форма, которую образованная дама может использовать лишь в общении с необразованной сельской девушкой, служанкой, напр. Елено, если ее имя Елена, но в общении со своей образованной подругой она должна учтиво обращаться к ней общей формой, т.е. Елена, как это принято в странах, где 
она училась. Таким образом создается определенная социолингвистическая дифференциация - общая форма является престижной, модной, типичной для людей с более высоким образованием и социальным статусом, а вокативная форма - непрестижной, типичной для людей с более низким образованием и социальным статусом. Ст. Младенов называет этот процесс обезьянья мода и отрицательно относится к нему, так как он нарушает тысячелетную специфику болгарского языка.

Несмотря на критику Младенова, теперь, почти сто лет спустя, можем отметить, что замещение вокатива личных имен женского, а теперь даже и мужского рода, общей формой стало нормой в языке СМИ и вообще при официальном общении, а поскольку все еще употребляются и вокативные формы этих имен, они стилистически маркированы как неофициальные, дружеские, иногда и не очень вежливые, даже грубые. Как известно, формы обращения личных имен используются не только с контактной функцией, но и как средство выражения определенного личного отношения к слушателю. Кроме того, в стремлении к оригинальности и экспресивности эти формы очень часто могут изменяться в истории языков, а могут быть связаны и с „языковой модой”, как в нашем случае. Историческое развитие болгарского языка показало, что официальная языковая политика не успела воспрепятствовать этой грамматикализации. В настоящее время общая форма как обращение еще не успела полностью устранить вокативную форму, но очень уменьшила сферу ее употребления из-за созданной дифференциации (социолингвистической и стилистической) между двумя формами (см. Първев 1978).

Интересно отметить, что это не единственный пример, когда давно грамматикализованное явление начинает слабо использоваться или вообще не употребляется в литературном языке из-за того, что оно не существует в престижных для определенных слоев общества иностранных языках и интеллигенция начинает его считать просторечным и ненужным. Исследователи подчеркивают, что в настоящее время из письменной речи турецкой интеллигенции начинают исчезать mіš-формы в качестве показателей косвенной эвиденциальности. Их замещают di-формами прямой эвиденциальности, несмотря на то что косвенная эвиденциальность существует в турецком языке еще с VIII в. и широко используется в устной речи (Basen, Feuillet 1980; Meydan 1996: 142). Теперь еще нельзя оценить, как в будущем будет развиваться этот процесс. Приведет ли он к исчезновению категории эвиденциальности в турецком языке, либо эта тенденция так и останется ограниченным явлением в письменной речи турецкой интеллигенции.

Причиной замедления грамматикализации неопределенного артикля един в болгарском литературном языке стала языковая политика в сороковые годы прошлого века. Может быть, на появление этой грамматикализации оказали известное влияние и европейские языки с неопределенным артиклем, что отмечает и Л. Андрейчин, ср. „Нужно избегать употребления един, една, едно, аналогичного употреблению неопределенного артикля в других языках,“ (Андрейчин 1944: 141). Это предписание в нормативной грамматике связано с широко распространенным взглядом в первой половине прошлого века, что языки не должны принимать чужеродные влияния в области грамматики, для того чтобы сох- 
ранить свою национальную самобытность. Надо иметь в виду однако, что хотя и грамматикализация един в качестве неопределенного артикля, вероятно, контактно индуцирована, болгарский язык развивается собственным путем, создавая шаг за шагом оппозиции в трехчленной артиклевой системе в зависимости от семантики выражаемой детерминации, от семантики имен и от семантики предложения (см. подр. Nicolova 2017:131-172). История болгарского языка показала, что языковая политика лишь некоторое время может влиять на развитие литературного языка, которое определяется множеством различных факторов.

\section{Выводы.}

Наши наблюдения показали, что факторы, препятствующие как установлению, так и дальнейшему развитию, интеграции в систему и повсеместному употреблению (во всех стилях и регистрах языка) результатов грамматикализаций очень разнородны и нередко проявляются комбинированно. Здесь мы наметим лишь некоторые из этих факторов, требующих подробного изучения.

1. Семантические факторы.

А) Если исходный элемент при грамматикализации - лексема или сочетание лексем.

а) Лексическое значение исходного элемента и связанные с ним конвенциональные импликации, которые могут привести к десемантизации сначала лишь в определенных конструкциях и контекстах, а позже и к приобретению нового грамматического значения, играет определяющую роль.

б) Лексико-семантическая комбинаторика конструкции, в рамках которой развивается новая граммема, тоже очень важна. Если наблюдаются трудности при такой комбинаторике, грамматикализация не может проявиться полностью, ее развитие останавливается на одном из этапов (напр. посессивный пассив).

Б) Когда исходный элемент при грамматикализации грамматический, конечный элемент может быть не принят в морфологическую систему. Интеграция не происходит в том случае, если он полисемантичен или очень близок по значению к существующим граммемам. Языковая система может не принять данную граммему, если в языке существуют другие синонимические средства, напр. лексические, которые более адекватно выражают подобное значение (напр. презумптив и синтетическое условное наклонение в болгарском языке). Стремление к экономии - важная языковая тенденция, которая может помешать определенной грамматикализации.

2. Формальные факторы: если исходный элемент морфема, важную роль играет морфотактика, которая может блокировать образование новых форм во многих случаях, так что грамматикализация не может развиться до конца. Кроме того, важную роль играет и комбинаторика ограничений при выражении грамматических значений отдельных элементов в конструкции.

3. Если данная грамматикализация приводит к дефективности в информационной структуре предложения, новая граммема менее „конкурентно способна" в сравнении с синонимическими граммемами (если таковые существуют), которые могут употреблятся без ограничений в коммуникативно-информа- 
ционной парадигме предложения, ср. экзистенциальный пассив с имa-habere и „нормальный” пассив с esse.

4. Социолингвистические факторы - спонтанная оценка данной грамматикализации обществом или его частью и ее оценка лингвистами, также могут сказаться на развитии грамматикализации, вплоть до ее устранения из определенного стиля, а в некоторых случаях даже из языка.

\section{Использованная литература}

Андрейчин, Любомир. Основна българска граматика. София: Хемус, 1944.

Герджиков, Георги. Преизказването на глаголното действие в бъллгарския език. София: Наука и изкуство. 1984.

ГСЕ 1991: Граматика на старобългарския език. Граматични очерци. София: Изд. на БАН, 1991. Мирчев, Кирил. Историческа граматика на българския език. София: Наука и изкуство, 1976.

Младенов, Стефан. „Убийството” на звателния падеж и други езикови неуредици”. Родна реч 5, 1927-1928: 213-216.

Ницолова, Руселина. „О затруднениях при грамматикализации. Посессивный перфект и экзистенциальный пассив в болгарском языке”. [В:] Е. Търпоманова, Б. Михайлова, В. Алексова (съст.) Балканското езикознание днес. Сборник в чест на 75-годишния юбилей на проф.д.ф.н. Петя Асенова. София: Унив. изд. „Св. Климент Охридски”, 2016, 140-152.

Поповић, Људмила. „Посесивна резултативна дијатеза у српском језику у порећењу са другим словенским језицима". [В:] Научни састанак слависта у Вукове дане. Иновациони процеси у српском књижевном језику - утицаји других језика и култура 43/1, Београд, 2014, 27-45.

Първев, Христо. „Звателните форми на собствените женски лични имена”. [В:] Петър Пашов (съст.) Помагало по българска морфология. Имена. София: Наука и изкуство, 1978, 223-237.

Чакърова, Красимира. „Към въпроса за синтетичното условно наклонение в съвременния български език”. Научни трудове на Пловдивския университет „Паисий Хилендарски”, т. 3, кн. 1. Филология, 1995, 79-86.

Bazin, L., J. Feuillet. „L' opposition constatation / non constatation en turc et en bulgare”. Zeitschrift für Balkanologie 16, 1980: 9-15.

Boye, Kasper, Peter Harder. „A usage-based theory of grammatical status and grammaticalization”. Language 88, 2012: 1-44. Brinton, Laurel J., Elisabeth Closs Traugot. Lexicalization and Language Change. Cambridge: CUP, 2005.

Bybee, Joan L. , Revere Perkins, William Pagliuca. The evolution of grammar: tense, aspect, and modality in the languages of the world. Chicago, London: The University of Chicago Press, 1994.

Fischer, Olga. „On problem areas in grammaticalization: Lehmann's parameters and the issue of scope." [In:] An Van Linden, Jean-Christophe Verstraete, Kristin Davidse (eds.), Formal evidence in grammaticalization Research. Amsterdam/Philadelphia: John Benjamins, 2010, 17-42.

Haspelmath, Martin. „The European Linguistic Area: Standard Average European”. [In:] Martin Haspelmath, Wulf Oesterreicher and Raible, Wolfgang (eds.). Language Typology and Language Universals, Handbücher zur Sprach- und Kommunikationswissenschaft. Berlin: Mouton de Gruyter, 2001, 1492-1510.

Heine, Berndt, Tania Kuteva. World Lexicon of Grammaticalization. Cambridge: CUP, 2002.

Heine, Berndt, Tania Kuteva. The Changing Languages in Europe. New York: Oxford University Press, 2006.

Hopper, Paul. J., Elizabeth Closs Traugott. Grammaticalization, $2^{\text {nd }}$. edn. Cambridge: Cambridge University Press, 2003.

Kuryłowicz, Jerzy. „The evolution of grammatical categories”. Diogenes 51, 1965, 55-71.

Kuteva, Tania, Berndt Heine. „An integrative model of grammaticalisation.” [In:] Wiemer, Björn, Bernhard Wälchli, Bernhard Hansen (eds.) Grammatical Replication and Borrowability in 
Language Contact. Berlin: De Gruyter Mouton, 2012, 159-190. [Series: Trends in Linguistics. Studies and Monographs [TiLSM] 242].

Lehmann, Christian. Thoughts on Grammaticalization. $2^{\text {nd }}$ revised edn. Erfurt: Seminar für Sprachwissenschaft, 2002.

Meillet, Antoine."L'evolution des formes grammaticales." Scientia (Rivista di scienza) 12, 1912: 384-400.

Métiyé Meydan, „Les emplois médiatifs de - miş en turc”. [In:] Zlatka Guentchéva (ed.) L'énonciation médiatisée. Louvain, Paris: Bibliothèque de l'Information Grammaticale, 1996. [Éditions Peeters].

Mitkovska, Liljana, Eleni Bužarovska. „On the use of habere-perfect in journalistic and administrative style. STUF 61/2, 2008: 128-138.

Nomachi, Motoki. "On the so-called possessive perfect in standard Serbian language (with a glance at other Slavic languages)". Leptir Mašna, the Literary Magazine of Students in Balkan Studies 9/1, 2012: 89-97.

Nomachi, Motoki. "Possessive Constructions in the South Slavic Languages: Some Implications for Areal Typology". [In:] Od Čikago i nazad: Papers to Honor Viktor A. Friedman on the Occasion of his Retirement $=$ Balkanistika (28), 2015, 337-355.

Nicolova, Ruselina. "Correlation between Formal and Semantic Changes in Grammaticalization". [In:] Grammaticalization and Lexicalization in the Slavic Languages. Proceedings from the $36^{\text {th }}$ Meeting of the Comission on the Grammatical Structure of the Slavic Languages of the International Committee of Slavists, München - Berlin - Washington/D.C.: Verlag Otto Sagner, 2014, 31-50.

Nicolova, Ruselina. Bulgarian Grammar. Berlin: Frank\&Timme, 2017.

Traugott, Elizabeth Closs, Graeme Trousdale (eds.) Gradience, Gradualness and Grammaticalisation. Amsterdam/Philadelphia: John Benjamins, 2010

Wiemer, Björn, Bernhard. Wälchli. "Contact induced grammatical change: diverse phenomena, diverse perspectives". [In:] Björn Wiemer, Bernhard Wälchli, Bernhard Hansen (eds.) Grammatical Replication and Borrowability in Language Contact. Berlin: De Gruyter Mouton, 2011, 3-66. [Series: Trends in Linguistics. Studies and Monographs [TiLSM] 242].

Wiemer, Björn, Bernhard Wälchli, Bernhard Hansen (eds.) Grammatical Replication and Borrowability in Language Contact. Berlin: De Gruyter Mouton, 2011. [Series: Trends in Linguistics. Studies and Monographs [TiLSM] 242].

Wiemer, Björn. "Quo vadis grammaticalization theory? Why complex language change is like words". Folia Linguistica 48/2, 2014: 425-467.

Wisher, Irene. "Grammaticalization". [In:] S.G. Thomason (ed.) Encyclopedia of Language and Linguistics. 2006, 129-135.

\section{Руселина Ницолова}

\section{О ФАКТОРИМА КОЈИ СПРЕЧАВАЈУ ГРАМАТИКАЛИЗАЦИЈУ}

\section{Резиме}

Граматикализација је градуелни инхерентни језички процес промена који може трајати током дужег историјског периода и водити настанку нове грамеме. Таква грамема се развија из лексеме или лексичког склопа, али и из друге грамеме. У раду се разматрају фактори који спречавају настанак и даљи развој резултата граматикализације, као и њихову интеграцију у систем и широку употребу у свим језичким стиловима и регистрима. Такви фактори се могу условно разврстати на четири типа: а) семантички фактори (ако је полазни елемент граматикализације лексема или лексички склоп), тј. лексичко значење полазног елемента и конвенцијалне импликације у вези са њим, лексичко-семантичка комбинаторика конструкције у чијим се оквирима 
развија нова грамема - изостанак интеграције крајњег резултата граматикализације у морфолошки систем је могућ уколико је његово значење блиско значењу грамема које већ постоје у језику или уколико постоје друга синонимијска средства лексичке природе која боље одсликавају то значење; б) формални фактори - морфотактика и др.; в) дефективност информационе структуре реченице; г) социолингвистички фактори - оцена граматикализације од стране друштва или његових утицајних делова, као и оцена од стране лингвиста.

Кључне речи: граматикализација, фактори који спречавају, бугарски језик. 